\title{
Aves seguidoras de correições de formigas nas Américas e África
}

\author{
Ant-following birds in the Americas and Africa
}

\author{
Edwin O. WILLIS
}

Yoshika ONIKI

\section{RESUMO}

O povo de lugares “desenvolvidos” presta muita atenção aos animais de fora da mata. Para saber o valor das matas tropicais, precisamos conhecer animais como as ferozes formigas de correição e suas aves seguidoras. Na zona neotropical, as chocas ficam sobre as "taócas" nos troncos pequenos verticais perto do chão. Há até 6 espécies de chocas juntas sobre uma correição numa zona equatorial, menos ao sul, ao norte ou nas serras. As aves grandes atacam as pequenas, mas estas ficam nas bordas da correição onde têm menos presas. Podem ocorrer alguns casais de cada espécie, aquele do território local sendo dominante sobre os demais. Os arapaçus sobem nos troncos grandes na mata, e as fêmeas de espécies pequenas ficam sem ajuda dos machos com os ninhos quando precisam voar para longe dos arapaçus maiores, e encontrar um local livre sobre as formigas para se alimentar. Não é o alimento abundante que permite à fêmea nidificar sozinha, mas o perigo do ataque de predadores quando o macho segue a fêmea no sub-bosque aberto. Nas matas mais baixas ou nas capoeiras, as saíras e outras aves monógamas, não correm tanto perigo, com os galhos protegendo e proporcionando poleiros perto do chão. Os cucos do tipo "bipbip” do deserto podem correr no chão junto às correições. No leste e oeste da África, há dezenas de aves seguindo as "formigas-safari”, mas não aquelas especialistas do Novo Mundo. Tem ave que anda no chão como um cuco, mas não têm os arapaçus ou as chocas nos troncos verticais. Os sabiás são abundantes na África, usando o chão ou galhos baixos como alguns sabiás na zona neotropical. Essas formigas não ocorrem na Ásia, assim a evolução é bastante diferente em diferentes matas tropicais.

Palavras-chave: Afrotrópicos, aves, correição de formigas, mata, neotrópicos. 


\begin{abstract}
People of "developed" regions pay much attention to animals outside the forest. To learn the value of tropical forests, it is good to know their animals, such as the army ants and the birds that follow them in the understory. In the neotropics, there are "armies" of Eciton and Labidus ants, with many birds following them to catch fleeing insects. Antbirds cling to small upright trunks, with up to 6 kinds at swarms near the equator, and less in uplands or away from the equator. Big birds attack small ones, which flee to swarm edges where there are few insects for big birds. Each species can have several pairs, the territory owners dominating visitors, but letting them stay. Woodcreepers climb up large trunks, females of small species not letting males help with nests because they have to fly far off when big paired woodcreepers take over the swarm. Small ones don't pair up because they could be predated in the open understory if he followed her. In second growth or low woods, tanagers and other monogamous pairs use low branches that protect them from predators and are sites for watching over ants. Cuckoos like "roadrunners" of open deserts run on the ground around ants. In eastern and western Africa, "safari ants" attract dozens of birds, including one that acts like a roadrunner, but there are no antbirds or woodcreepers adapted for vertical trunks. There are many thrushes, using the ground or low twigs near ants, as in the neotropics. Asia lacks these ants, tropical forests vary greatly in evolution of ants and ant followers.
\end{abstract}

Index terms: Afrotropics, army ants, birds, forests, Neotropics.

\title{
Introdução
}

Como tem sido apontado pelo prof. Ângelo Machado (com. pess.), nos países tropicais, as impressões da natureza são fortemente marcadas pela literatura européia e norte-americana. As crianças aprendem a desenhar árvores de regiões temperadas, com as copas pontudas para interceptar a luz solar lateral das latitudes árticas ou do sul, ao invés de coroas achatadas das árvores que enfrentam, de cima, o sol equatorial. Conhecemos melhor os lobos europeus do que os nossos lobos-guarás; sabemos mais sobre os leões das savanas africanas do que das onças 
amazônicas. É hora de voltarmos as nossas atenções para nossas próprias florestas que abrigam animais tão interessantes quanto àqueles do mundo desenvolvido. Entre esses animais tropicais estão as taócas, ou formigas de correição, e as aves que as seguem.

Nas florestas desde o México até a Argentina, incluindo parte do Estado de São Paulo e todos os outros estados brasileiros, as taócas quando unidas pelas suas pernas dentro de seus "ninhos" ou "bivaques” chegam por vezes à uma colônia do tamanho de uma jaguatirica. Nas florestas africanas, as colônias de uma formiga perigosa e aparentada às taócas chegam a volumes ainda maiores, de 22 milhões de indivíduos, metade do tamanho de um leopardo.

Poucas pessoas têm a noção de que estas "taócas” ou "saca-saias” ou “marabuntas” são regularmente seguidas por várias espécies de animais, que capturam insetos e outros organismos pequenos que são afugentados pelas formigas em marcha.

Em alguns filmes de florestas, as taócas ou formigas safari ("safari” é uma palavra Swahili, língua franca do leste da África, que quer dizer “viagem”), são confundidas com as formigas cortadeiras como a saúva e as formigas quenquéns. Os cientistas, entretanto, sabem que as verdadeiras formigas de correição são nômades e carnívoras. Com suas fortes mandíbulas, elas cortam os pequenos animais capturados, principalmente artrópodes, e carregam as peças de volta para o ninho temporário, formado por todos os indivíduos que se ligam uns aos outros com suas longas pernas formando a massa viva e pulsante que constitue o "ninho" ou "bivaque”. A rainha e milhares de larvas são protegidos pelas mandíbulas e ferrões de centenas de milhares de soldados e operárias, formando tecidos vivos pendurados do tronco de uma árvore ou em um buraco no chão. De tempos em tempos, a colônia inteira se desfaz e se locomove para um novo local de “nidificação”, dependendo em parte de seus ciclos reprodutivos. 


\section{Principais espécies de formigas}

As principais espécies de formigas de correição na região neotropical são Eciton burchelli, de cor marrom na parte anterior e laranja claro no abdomem, com cerca de $10 \mathrm{~mm}$ de comprimento e Labidus praedator, uma espécie de formigas pretas e pequenas. Ambas formam largas frentes de caçada de milhares de indivíduos, movendo-se à razão de 5-15 metros por hora, através do chão da floresta e outras vegetações sombreadas. Às vezes, podem sair na zona aberta.

Eciton burchelli envia colunas laterais de caçadas que sobem os troncos das árvores e adentram os emaranhados no chão e acima dele. O bivaque e as colunas de caçada raramente são cobertos pela terra, exceto nas regiões frias. Devido à sua atividade na superfície, são muito sensíveis ao calor do sol e ao frio do inverno ou das montanhas acima de $1.400 \mathrm{~m}$ de altitude. Este tipo de formiga de correição é importante para as aves, porque caçam o dia inteiro mesmo na estação seca, nunca passando à caça noturna em qualquer época do ano. É resistente à seca, desde que existam áreas grandes de mata sombreada para percorrerem a cada dia.

Labidus praedator tem ninhos subterrâneos e as trilhas são cobertas de terra desde o ninho até a frente de caçada. Como resultado, é relativamente insensível ao frio ou calor, e ocorre mesmo nos cerrados quentes, gramados da Universidade Estadual Paulista (UNESP) de Rio Claro, ou florestas frias em topo de montanhas onde E. burchelli não pode sobreviver. Entretanto, L. praedator evita o clima seco, enviando suas colunas de caçada principalmente à noite ou após a chuva (daí seu nome de “formiga de chuva”), e assim, é seguido pelas aves com dificuldade.

As formigas-safari da África, do subgênero Anomma e gênero Dorylus, são minúsculas formigas pretas. Assemelham-se a L. praedator, pois nidificam subterraneamente, vivem mesmo em montanhas altas e frias 
ou áreas quentes de savana, e emitem colunas de caçada à noite ou após as chuvas para evitar o clima seco. Entretanto, as formigas safari, muitas vezes, formam colônias bem grandes. Uma das espécies da África Ocidental, Dorylus (Anomma) wilverthi, algumas vezes tem correições coordenadas de $50 \mathrm{~m}$ de largura, portanto muito mais larga do que as frentes de caçada de $15 \mathrm{~m}$ de largura de uma grande colônia de E. burchelli ou as de $10 \mathrm{~m}$ de L. praedator. Também, as formigas africanas têm as mandíbulas que se cruzam como as tesouras e, portanto, podem cortar mesmo os animais grandes como o homem ou a carne estocada. As taócas neotropicais picam e mordem, mas são incapazes de cortar a carne de vertebrados. Apenas separam os artrópodes em suas juntas; não são tão perigosos ao homem quanto às formigas safari. Curiosamente, as florestas tropicais da Ásia não têm formigas de correição, talvez porque este tipo de predador nunca evoluiu por lá.

Nas florestas tropicais, quando as formigas de correição ou formigas safari avançam em suas caçadas, pequenos animais voam e saltam em todas as direções fugindo de suas poderosas mandíbulas. Mesmo os animais grandes como sapos e ouriços, têm de sair da frente. Em conseqüência, há muitos outros animais que viram nisto um meio fácil de captura de presa próxima às formigas. Entre os seguidores de formigas estão as moscas parasitas (família Tachinidae), os lagartos insetívoros (Teiidae e Iguanidae na região neotropical, Scincidae em ambos os hemisférios), um macaco ocasional (Cebidae e Callicebidae nos neotrópicos, chimpanzés na África), mangustos (Viverridae) de dia e morcegos (Chiroptera) e galagos (Galagidae) à noite na África. Temos visto até gatos domésticos perseguindo baratas que foram afugentadas pelas taócas, e pequenos peixes pegando os insetos que pularam na água quando as correições passavam perto de riachos. 


\section{O comportamento de seguir formigas}

O comportamento de seguir as formigas é semelhante àquele de seguir outros animais ou máquinas que espantam os artrópodes, assim como os falcões (Falco femoralis) seguem os trens, as manadas ou o fogo nas savanas e campos. Em nenhum caso há a necessidade para os seguidores alimentarem-se dos animais ou máquinas, que afugentam as presas. Não é correto pensar que as formigas são, também, comidas pelos seguidores. Provavelmente elas são muito duras, têm poucas partes digeríveis, ou são muito agressivas e de mau paladar. Assim não é correto chamar as aves de “papa-formigas”, pois quase nenhuma ave come estas formigas exceto, de vez em quando, um trinca-ferro (Saltator).

Entre os animais que seguem as formigas, as aves são especialmente importantes. Existe, até mesmo, uma família de aves, as chocas ou Formicariidae neotropicais, que derivam o seu nome da associação de alguns de seus membros com as formigas. As chocas compõem uma família (atualmente dividida em Formicariidae e Thamnophilidae) de cerca de 240 espécies, habitantes de florestas e matas secundárias desde o México até a Argentina. Cerca de 50 espécies têm sido registradas em algumas localidades amazônicas. Com tantas espécies, nem todas seguem as formigas. Algumas vivem no topo das árvores, nos níveis medianos das florestas, em emaranhados densos de cipós, em emaranhados de taquaras ou nas várzeas. Somente umas poucas espécies que vivem próximo do chão seguem as formigas regularmente, incluindo cerca de uma espécie em cada 10 na família.

Em florestas equatoriais extensivas, várias espécies de chocas podem ocorrer em uma única correição de formigas. No Panamá, onde estudamos o fenômeno por muitos anos na famosa estação biológica da Ilha de Barro Colorado, três espécies de chocas seguiram regularmente as formigas. Na 
alta Amazônia, cinco ou seis espécies ocorrem em algumas localidades. Como podem tantas espécies de aves seguir uma única colônia de formiga quando “cada macaco deve ter o seu galho?” Acontece que algumas chocas usam pousos horizontais e portanto favorecem a mata secundária e outros locais semi-abertos, onde há luz suficiente paras as folhas em ramos horizontais se desenvolverem próximo ao chão. Outras chocas seguem as formigas somente no interior sombrio da mata, pousando de lado em ramos finos que se alongam verticalmente para alcançar a luz acima. Somente as espécies de aves com pés e pernas especialmente fortes podem fazer isto e a maior delas pesa apenas 55 g. A espécie maior pode atacar as demais, tomando os seus pousos, se elas começam a capturar muitas presas.

As espécies grandes têm de encontrar os centros agitados de correições grandes de formigas, para obter suficiente alimento por hora para suportar seus corpos grandes, deixando, portanto, as bordas das correições e as pequenas correições laterais para as chocas menores. Normalmente haverá também, chocas de tamanho médio ou $35 \mathrm{~g}$ e pequenas chocas periféricas de $17 \mathrm{~g}$, seguindo as formigas em qualquer região equatorial. No sul do Brasil, onde as formigas de correição são menos frequentes, somente sobrevivem chocas de tamanho médio (olhos-de-fogo-do-sul, Pyriglena leucoptera). Ao norte de Honduras, nenhuma choca segue as formigas, e um tiê de tamanho médio (Thraupidae, Habia fuscicauda) é o substituto.

Ao norte do Rio Amazonas, desde o Amapá até o norte do Peru, uma quarta espécie de choca consegue juntar-se às demais espécies de três tamanhos normalmente presentes na floresta. Pithys albifrons, a mãe-detaóca-de-topete, é uma pequena choca de cores vivas de 21 g, que sobrevive sobre as formigas de correição voando rapidamente e mantendo-se atrás das aves maiores. Portanto, ela pode até infiltrar-se no centro de grandes correições, fugindo rapidamente se for atacada, mas voando velozmente em uma fração de segundo para apanhar um inseto. Se o ataque continua, $P$. albifrons tem de voar grandes distâncias para encontrar uma outra correiçao. 
Uma única ave tem de ter uma área florestada de pelo menos $3 \mathrm{~km}$ de diâmetro, ou ela não terá suficiente colônias de formigas para seguir em dias quando as aves maiores dominam as boas colônias. Esta é, portanto, uma ave rara, uma que facilmente irá à extinção em parques com menos de 10 km de diâmetro.

Curiosamente, $P$. albifrons é uma das aves mais comuns nas redes de neblina estendidas para capturar as aves nos sub-bosques das florestas em Manaus (quando a floresta é extensa). A razão não é que a ave é comum, mas que ela voa longas distâncias próximo ao chão todos os dias quando está procurando as formigas. Portanto, cada indivíduo é repetidamente recapturado, e logo capturamos com poucas redes todas as aves num raio de $3 \mathrm{~km}$. As redes de neblina podem dar a falsa impressão sobre o número de aves em um caso como este.

As chocas seguidoras de correição, geralmente, requerem grandes áreas de floresta para sobreviver, porque há poucas colônias de formigas ativas por quilômetro quadrado. Em conseqüência, estas aves são muito propensas à extinção a menos que extensas áreas de mata sejam preservadas. A Ilha de Barro Colorado, embora uma famosa reserva natural, tem somente $15 \mathrm{~km}^{2}$ de mata. Esta área não é suficiente, pois mesmo com a completa proteção, as aves estão desaparecendo de lá. Duas ou três espécies panamenhas seguidoras de formigas já haviam desaparecido da Ilha antes que iniciássemos os trabalhos lá nos anos 60 . Uma terceira espécie desapareceu em 1969, enquanto uma quarta espécie chegou a ter uma fêmea e cinco machos sobreviventes durante o ano seco de 1968; os últimos dois dos machos desapareceram após 1977. Somente quatro espécies pequenas seguidoras de formigas ainda vivem na Ilha, embora haja suficientes formigas. Cerca de 40 outras espécies de aves, uma vez presentes na Ilha, também já desapareceram desde os primeiros levantamentos nos anos de 1920. Para proteger as aves, um parque tropical deve ser maior que $15 \mathrm{~km}^{2}$. Antes de iniciarmos os estudos, ninguém imaginava que tais aves pequenas pudessem desaparecer de parques protegidos deste tamanho. Uma vez que os grandes parques são raros, os cientistas temem que muitas espécies sejam extintas com o desmatamento tropical. 
Quando iniciamos nossos estudos, ninguém sabia como as aves seguidoras de correição poderiam nidificar e manter seus territórios, seguindo as formigas nômades que se locomovem constantemente. Acontece que as aves começam a nidificar quando há muitas colônias de formigas presentes. Raramente, um par que está nidificando, teve de viajar mais que 400 m para encontrar uma colônia de formigas, pelo menos no Panamá. Em Manaus, onde estudamos P. albifrons e oito outras espécies seguidoras de correições, somente $P$. albifrons e, talvez, o arapaçu Dendrocincla merula tiveram de viajar regularmente mais de $400 \mathrm{~m}$ das correições para seus ninhos.

Acontece que algumas chocas mantêm territórios quando seguindo as formigas. Certas chocas pequenas seguem as formigas somente em dias quando as formigas atravessam seus territórios, e em outros dias, tem pouco o que comer. Para uma ave pequena que necessita pouco alimento, isto pode não ser um problema. As chocas grandes ou de tamanho médio tentam seguir as formigas constantemente, e assim, têm de segui-las fora de seus territórios, por muitos dias a cada ano. Isto significa que pode haver dois, três ou quatro pares de uma espécie de choca seguindo uma dada colônia de formigas. Na maioria dos casos, o par que domina é aquele que acontece estar em seu próprio território. Outros pares são atacados se eles pousam em ramos que o par dominante quer. Assim que as formigas nômades viajam umas poucas dezenas de metros, cruzando os limites do território do próximo par, este par repentinamente torna-se o par dominante. Outras chocas têm sistemas sociais ainda mais sofisticados nos quais os territórios não são tão óbvios. No caso de Phaenostictus mcleannani do Panamá, o sucesso vai para os grupos formados de "ligas” ou "clãs” de avós, pais e jovens. Outros, tais como em Pithys albifrons, parecem não manter territórios.

Em adição às chocas, outras aves de famílias neotropicais seguem as formigas de correição. Certos tipos de arapaçus seguem regularmente de 
formigas. Os arapaçus são aparentados ao joão-de-barro (Furnarius rufus, Furnariidae), e como este, tende a ser amarronzados na plumagem. Entretanto, as penas pontudas da cauda dos arapaçus permitem-nos galgar os troncos de árvores como os picapaus. Não são picapaus (Picidae), mas enganam algumas pessoas que os chamam por este nome. Ao invés de ninhos de barro, os arapaçus nidificam em cavidades de troncos de árvores, sem poder cavar o ninho à maneira dos picapaus, pois seu bico é frágil. Os arapaçus podem pousar verticalmente em grandes troncos de árvores, largos demais para as chocas usarem. Toda vez que as formigas passam ou sobem um grande tronco de árvore, as chocas se afastam e os arapaçus se regalam.

A única exceção é o arapaçu-da-taóca, Dendrocincla merula. Estas aves amazônicas usam ramos finos verticais assim como as chocas. $D$. merula tem muito sucesso ao norte do Amazonas e leste do Rio Negro, onde não há uma choca grande de 55 g. Lá, ela pesa 55 g e ocupa os ramos mais finos acima dos centros de correições. No resto da Amazônia, D. merula torna-se uma ave relativamente rara, perseguindo as chocas de $35 \mathrm{~g}$, mas sendo perseguido pelas de $55 \mathrm{~g}$.

Poucas chocas seguidoras de formigas vivem em florestas secas subequatoriais ao norte da Nicarágua, permitindo que uma segunda espécie de dendrocincla, $D$. anabatina trabalhe baixo em troncos finos ou grossos acima das formigas. Uma terceira espécie, D. homochroa, trabalha mais alto nos troncos. Uma quarta espécie, D. fuliginosa, trabalha em troncos grandes acima das formigas desde a Nicarágua para o sul, onde as chocas grandes bloqueiam as agressivas $D$. anabatina e D. homochroa. No sul do Brasil, D. fuliginosa é substituída por D. turdina, uma forma aparentada. Todos os quatro destes arapaçus de 40-50 g podem forragear no alto dos troncos, longe das formigas, diferentemente das chocas, quando o clima é muito frio ou seco para a atividade de formigas. Podem até seguir os bandos de coatís. Os dias de clima desfavorável tornam-se mais frequentes à medida que nos afastamos da zona equatorial, dando aos arapaçus de 
tamanho médio algumas vantagens sobre as chocas de tamanho médio. Nos Andes frios da Colômbia e região, o grande D. tyrannina segue as formigas porque não há chocas.

Os arapaçus grandes também seguem as formigas. Em Manaus, Hylexetastes perrotti de 125 g, Dendrocolaptes picumnus de 85 g, e Dendrocolaptes certhia de $60 \mathrm{~g}$ seguem as formigas, acompanhados de $D$. merula e $D$. fuliginosa. Longe da linha do equador, entretanto, sobrevivem somente as dendrocinclas e um ou outro Dendrocolaptes de $60 \mathrm{~g}$. No sul do Brasil, este arapaçu de 60 g é Dendrocolaptes platyrostris; na América Central é D. sanctithomae ou (em florestas úmidas das serras e montanhas) D. picumnus. Todos estes arapaçus grandes esperam pousados em grandes troncos e voam para a folhagem distante ou para o chão para apanhar a presa, atacando as chocas ou os pequenos arapaçus no caminho. Entretanto, eles são muito desajeitados quando têm de usar ramos mais finos, e as chocas ou os pequenos arapaçus são mais eficientes.

Os grandes troncos são relativamente esparsos, mesmo nas florestas altas, levando à falta de alimentos para os arapaçus, especialmente as espécies menores e menos dominantes. Como resultado, as fêmeas famintas são muitas vezes agressivas para com os seus machos e jovens. Os grandes Hylexetastes perrotti, que podem afugentar todas as outras espécies, são bem alimentadas e podem tolerar o seu único jovem crescido e seu par, durante todo o ano. Os relativamente grandes Dendrocolaptes spp. expulsam seus jovens para longe, após uns poucos meses, e as fêmeas atacam os seus pares para tomar os seus lugares toda vez que eles começam a pegar muitos insetos.

As fêmeas de arapaçus, que são de tamanho médio, geralmente, evitam ou atacam os seus machos, tolerando-os somente, por poucos dias, antes da nidificação e em seguida, criando sozinha os seus filhotes. Em um caso, D. merula em Manaus, os machos atacaram as fêmeas e em outras ocasiões, cortejaram duas ou mais fêmeas. Esta espécie pode ser 
semipromíscua, aproximando-se do padrão reprodutivo onde os machos cantam ou dançam para atrair tantas fêmeas quanto possível (como em beija-flores e tangarás). O macho de $D$. tyrannina dos Andes até canta por horas a cada dia de manhã, parecendo uma “araponga do sub-bosque”.

Recentemente, indicamos que as fêmeas de espécies promíscuas são justamente aquelas fêmeas que se deslocam grandes distâncias em ambientes perigosos para localizar alimentos. As dendrocinclas precisam deslocar-se muito em volta de cada correição ou, para outra correição distante, para evitar os grandes arapaçus dominantes. Há poucas folhas para se esconder de coruja ou falcão Micrastur, nos níveis médios dentro da mata escura. (Os beija-flores, os dançadores, as arapongas e as aves-de-paraíso ficam também em perigo, dentro da sombra e longe das folhas das copas ou próximo ao chão). Nestes casos, as fêmeas vagantes atacam ou evitam os machos, em vez de formar casais permanentes com eles, porque eles podem pegar alimento ou atrair os predadores. Assim, os machos abandonados precisavam tornar-se "promíscuos", procurando atrair fêmeas com cantos ou plumagens exageradas. Uma teoria anterior, defendida até recentemente pelos cientistas do hemisfério norte, foi que a "abundância" de frutos ou néctar poderia levar os machos a se tornarem indolentes e promíscuos, pois não precisavam auxiliar as fêmeas com a nidificação. Esta idéia não funciona para os papagaios e periquitos ou tiês frugívoros, onde o macho segue a fêmea o tempo todo. Em parte, a nova teoria, de falta de alimentos e perigo no interior da mata como pré-condições para a promiscuidade, resultaram das observações de fêmeas agressivas de arapaçus seguidores de correições e do fato que é a fêmea que se torna promíscua, com pouco alimento e território grande, e não a fêmea que se desloca pouco, com mais alimento.

Em adição às chocas e arapaçus, umas poucas espécies de saíras, sanhaçus e tiês (Thraupidae) seguem as formigas neotropicais. A maioria dos traupídeos são aves de cores vivas e de vôo rápido que utilizam ramos 
horizontais em copas ensolaradas ou margens da floresta. Umas poucas espécies descem para perto das formigas de correição, toda vez que as chocas são raras com falta de colônias, e os ramos horizontais comuns. No sul do Brasil, o tiê-de-topete, Trichothraupis melanops, se alimenta de frutos e insetos longe das formigas, mas também visita as poucas correições regularmente. Ela ataca até o olho-de-fogo-do-sul (Pyriglena leucoptera) que tem o seu mesmo tamanho, mas que não voa bem. Ao norte de São Paulo para o norte, o tiê-de-cabeça-cinza, Trichothraupis (Eucometis) penicillata, consegue seguir as formigas nas matas secas e várzeas, porque as chocas, seus competidores, têm dificuldade em atravessar as zonas secas ou canais de rios devido às suas adaptações à mata sombria, especialmente asas fracas e o desgosto pela luz solar intensa. No interior do Brasil e ao norte dos Andes, T. penicillata muda-se para as florestas secas e se dá muito bem, porque as chocas não gostam de matas semi-abertas onde há muitos ramos horizontais para uso dos tiês. Quando várias outras aves seguidoras de correição desapareceram de Barro Colorado, T. penicillata tornou-se comum, bem no interior da floresta, mesmo que ela tivesse de ficar de pé no chão porque aí os ramos horizontais são raros. Habia fuscicauda, um tiê que segue as formigas na América Central, utiliza também os ramos horizontais às margens da floresta, ao invés dos ramos verticais de matas que as chocas e arapaçus favorecem. No nordeste do Peru, há a recentemente redescoberta Pithys castanea nas matas arenosas, talvez tomando o lugar dos tiês.

A outra família neotropical com seguidores regulares de correição, é aquela dos cucos (Cuculidae). Até as almas-de-gato (Piaya) e anús (Crotophaga, Guira) seguem as formigas nas bordas das matas. Umas poucas espécies de cucos, notavelmente o "roadrunner” (Geococcyx velox) dos desertos norte-americanos e dos desenhos animados, correm pelo chão. Poucas pessoas conhecem as aves de $350 \mathrm{~g}$ aparentadas de G. velox, chamados jacus-estalos (gênero Neomorphus), que ocorrem ao redor das 
correições de formigas nas florestas desde o Rio Doce, Minas Gerais, até a Nicarágua. Com o tamanho de pequenos jacús, elas estalam os seus bicos e levantam as suas cristas e longas caudas antes de atacar as aves menores em perseguição a insetos, justamente como os seus parentes dos desertos do norte. Se tivéssemos de produzir desenhos animados para as crianças, o nosso “bip-bip” seria até mais interessante que aquele do norte. São aves em extinção com os desmatamentos na Mata Atlântica e outras áreas.

Muitos outros tipos de aves ocasionalmente seguem as formigas neotropicais. Temos visto galinhas seguindo as formigas, os inhambus ou os jacús e os jacamins correndo atrás de insetos próximos às formigas, os sabiás ou as gralhas e os bentevís descendo até as formigas. Por vezes, os gaviöes e os falcões das florestas seguem as formigas. Em alguns casos, eles atacam as aves, mas em outras, eles perseguem os insetos, as aranhas ou os escorpiões. Mesmo os tucanos podem seguir as formigas, assim como os udus e muitas outras aves menores.

As aves migratórias, visitantes do sul ou da América do Norte, podem seguir as formigas. A maioria destas aves migratórias é relativamente desajeitada na presença das formigas ou perdem a batalha em lutas com as aves seguidoras regulares. Frequentam mais as correições de formigas Labidus, onde tem menos seguidores regulares porque a correição raramente é ativa por muitas horas ao dia ou por dias seguidos.

O número total de espécies e indivíduos seguindo uma dada correição de formigas pode variar até 20 ou mais espécies e, até 50 ou mais indivíduos, de um dia para o outro. Em regiões secas, quentes ou frias, em mata secundária, matas de galerias ou fora da floresta, os números médios de aves são inferiores. Doze é o número máximo de espécies regulares seguidoras de correição, no oeste da Amazônia. (A palavra "profissional” não é mais usada para uma ave regular; e “obrigatória” também não deve ser usada porque implica que a ave nunca usa outra fonte de alimento. Geralmente, seguem as queixadas ou até os macacos quando faltam as 
taócas. Skutch, na Costa Rica, já treinou Gymnopithys na sua mata a seguílo, e Pyriglena perto de Rio Claro, nos segue quando estamos limpando as trilhas). O número descresce para cerca de 10 espécies, na Amazônia Central e para 8, em Belém. No oeste dos Andes, o máximo é cerca de 10 nas florestas úmidas e decresce a 3 ou 4 espécies nas florestas secas ou matas ao norte da Nicarágua. Nas matas do sudeste brasileiro, há apenas 4 a 5 espécies regulares na maioria das regiões. Em pequenos tratos de mata, a maioria das espécies desaparece.

Os grandes rios na Amazônia, muitas vezes têm diferentes combinações de aves seguidoras de correição em diferentes margens. Um exemplo, já notado, é que as chocas de 45-55 g ocorrem ao sul do Rio Amazonas, mas nunca conseguiram atravessar este rio. O número total de espécies seguidoras de correição é geralmente semelhante nos dois lados de um rio da Amazônia, mas os tipos de aves envolvidos podem ser diferentes. Por exemplo, há 5 espécies de arapaçus seguidores de formigas e 4 de chocas no Amapá, mas 3 espécies de arapaçus, 3 chocas, um tiê e 1 cuco próximo a Belém no Estado do Pará. Evidentemente, não há uma lei que regula a distribuição dos tipos de aves seguindo as formigas, mesmo que possa existir uma lei que regula o número máximo de espécies presentes (“macacos num só galho”). Pode haver diferenças entre as florestas das baixadas ribeirinhas e as de terra firme que estão distantes uns poucos quilômetros, como em Andoas no nordeste do Peru. Lá, as chocas Rhegmatorhina melanosticta e Pithys albifrons seguem as formigas principalmente em terra firme e Myrmeciza fortis e Gymnopithys lunulata principalmente ao longo do rio Pastaza (no passado, P. castanea nas matas arenosas; agora, estas matas perto do rio Amazonas).

Quando nos locomovemos através do Oceano Atlântico para a África, descobrimos que os tipos de aves seguindo as formigas safari são completamente diferentes daqueles nas regiões neotropicais. Quase nenhuma ave pousa em troncos finos ou grossos nas florestas africanas, 
exceto por umas poucas espécies de Pycnonotidae. Alguns representantes seguem as formigas, principalmente Bleda eximia e $B$. syndactyla no oeste da África, mas somente a última espécie regularmente pousa atravessado em ramos verticais como as chocas. Como alguns deles, têm o pé sindáctilo, com dois dedos juntados na base para melhor segurar em um ramo vertical.

Outras aves que seguem as formigas safari são principalmente os sabiás e parentes (Turdidae). Algumas espécies de sabiás seguem formigas nas matas neotropicais, mas evitam as correições com muitas chocas e arapaçus. Os sabiás não usam os ramos verticais dentro de florestas tanto quanto as chocas e os arapaçus, mas isso não é problema na África - pois lá as chocas e os arapaçus nunca foram evoluídos. Os sabiás têm de esperar em ramos horizontais bem à frente das formigas, ou usar o chão, portanto, têm, às vezes, de voar ou saltar longas distâncias para atingir a presa. Na estação biológica de Makokou, no Gabão, duas espécies de Alethe de 35 g e duas de Neocossyphus de 45-55 g seguem as formigas, assim como duas espécies de Pycnonotidae.

As enormes correições de algumas formigas africanas podem atrair grande número de aves. Willis (1986) anilhou (com anilhas coloridas) cerca de 50 indivíduos de Alethe castanea em uma única colônia em Makokou, e viu cerca de 100 aves de 15 espécies nesta colônia em alguns dias. Certos calaus (Tropicranus albocristatus, Bucerotidae), aves que se assemelham aos tucanos brancos e pretos, seguem os macacos em alguns dias e formigas em outros. Às vezes, um gavião (Accipiter tachiro), que parece o nosso falcão Micrastur, ataca as aves ou artrópodes grandes. Uma ave frugívora, o turaco-verde-e-vermelho (Turaco macrorhynchus), às vezes, desce para perto das correições para procurar frutos caídos no chão. Esta ave aproveitase das aves em volta das formigas, não das formigas. Com tantas aves em volta, o turaco pode ter certeza de que vai ser avisado se houver qualquer gavião ou mangusto predador nas vizinhanças. 
Ao invés de cucos correndo atrás das formigas, os grandes Picathartes sp. (Picathartidae), de cauda longa pulam nas bordas das correições no oeste da África. Encontramos estes Picathartes nas matas serranas, próximas à cidade de Freetown, em Serra Leoa, e nas matas do interior da Libéria. Com cabeças parcialmente nuas e seus hábitos incomuns de nidificação em cavernas e comendo baratas atraídas pelo guano de morcegos, essas aves poderiam ser objetos para desenhos animados das crianças tão bons quanto Geococcyx velox. Em Tanganyika e Ruanda, no leste da África, onde o clima é seco e as florestas existem principalmente no topo das montanhas, uma ou duas espécies do gênero Alethe é o número normal de aves regulares junto às correições. Em geral, as formigas africanas são difíceis de serem seguidas pelas aves porque elas, muitas vezes, caçam à noite. Isto auxilia os morcegos e os galagos, mas reduz a lista de aves. Já observamos os galagos pulando entre os troncos verticais de 1-3 m de distância, ao cair da noite na mata de Makokou.

É interessante que na África ocorram os pequenos “macacos" noturnos (galagos) atrás das formigas, mas nada semelhante ocorre no Novo Mundo. Na África, há evolução de aves parecidas com os cucos terrestres daqui, mas nunca apareceram aves adaptadas para pousar em troncos ou ramos verticais, a exemplo de nossos arapaçús e chocas. Assim, a evolução pode produzir animais semelhantes na África e Américas, mas em outros casos podem faltar tipos importantes de animais aqui ou lá. Lembramos que o homem apareceu na África, e somente chegou aqui a poucos milhares de anos atrás, como imigrante. A garça-vaqueira (Bubulcus íbis) chegou aqui a cerca de 100 anos atrás, atravessando o oceano. A evolução convergente pode ocorrer, como ocorreu com as formigas de correição lá e aqui, mas também pode faltar (como faltam essas formigas na Ásia).

As aves seguidoras de correição têm produzido várias teorias novas na ciência, e é apenas lamentável que ainda se conheça tão pouco sobre elas. Espera-se que as aves seguidoras de correição da África e das Américas 
venham a substituir alguns animais do norte em nossa literatura, e mesmo de idéias transmitidas às crianças sobre os habitantes das florestas.

Se não cortamos muito de nossas florestas ou aquelas da África, talvez haja tempo para que as pessoas de zonas tropicais aprendam sobre nossos animais ao invés de aprender somente sobre os animais do hemisfério norte. É mais fácil estudar animais na cidade em locais abertos ou em cativeiro, mas não devemos nos esquecer dos animais de vida livre das matas tropicais. Devemos nos lembrar que as galinhas vêm das matas da Ásia!

AGRADECIMENTOS - Agradecemos às diversas financiadoras que ao longo dos anos premiaram com sua confiança e apoio aos nossos projetos e aos dois revisores anônimos que nos auxiliaram a melhorar a apresentação do texto. Publicação no. 52 do Instituto de Estudos da Natureza, Rio Claro, SP.

\section{Referências bibliográficas}

STOTZ, Douglas, (1992). Buff-throated Saltator eats army ants. Wilson Bulletin, U. S. A., v. 104, n. 2, p. 373-374.

WILLIS, Edwin O’Neill, (1960). A study of the foraging behavior of two species of ant-tanagers, Auk, U. S. A., v. 77, n. 1, p. 150-170.

(1967). The behavior of Bicolored Antbirds,

California, Univ. Calif. Publ. Zoologia, U. S. A., n. 79, p. 1-132.

(1985).East African Turdidae as safari ant

followers, Le Gerfaut, Belgium, v. 75, n. 1, p. 140-153.

, (1986). West African thrushes as safari ant

followers, Le Gerfaut, Belgium, v. 76, n. 1, p. 95-108. 
, (1995). On Dendrocincla

tyrannina: morphology, behavior and conservation of a shy lek-type insectivore. Caldasia, Colombia, v. 18, n. 1, p. 131-140.

in Cinnamon-vented Pihas (Lipaugus lanioides, Cotinginae, Tyrannidae), Ornitologia Neotropical, Canada, v. 9, n. 1, p. 129-159.

\section{Autores}

\section{Edwin O. Willis}

Departamento de Zoologia, UNESP, C. P. 199, 13.506-900 Rio Claro, SP e Instituto de Estudos da Natureza, Rua 2 no. 2272, Centro, 13.500-153 Rio Claro, SP. Brasil

Professor titular Doutor aposentado do Departamento de Zoologia, UNESP, Rio Claro, SP. e Doutor Pesquisador, Instituto de Estudos da Natureza, Rua 2 no. 2272, Centro, 13.500-153 Rio Claro, SP, Brasil.

ewillis@rc.unesp.br

\section{Yoshika Oniki}

Doutora Pesquisadora, Instituto de Estudos da Natureza, Rua 2 no. 2272, Centro, 13.500-153 Rio Claro, SP, Brasil.

\section{Como citar este artigo:}

WILLIS, Edwin O.; Yoshika ONIKI, Yoshika. Aves seguidoras de correições de formigas nas Américas e África. Revista ACOALFAplp: Acolhendo a Alfabetização nos Países de Língua portuguesa, São Paulo, ano 2, n. 4, 2008. Disponível em: <http://www.mocambras.org > e ou $<$ http://www.acoalfaplp.org>. Publicado em: março 2008. 